\title{
Attributing Human Foodborne Diseases to Food Sources and Water in Japan Using Analysis of Outbreak Surveillance Data
}

\author{
Kumagai, Yuko; Pires, Sara Monteiro; Kubota, Kunihiro; Asakura, Hiroshi
}

Published in:

Journal of Food Protection

Link to article, DOI:

10.4315/JFP-20-151

Publication date:

2020

Document Version

Peer reviewed version

Link back to DTU Orbit

Citation (APA):

Kumagai, Y., Pires, S. M., Kubota, K., \& Asakura, H. (2020). Attributing Human Foodborne Diseases to Food Sources and Water in Japan Using Analysis of Outbreak Surveillance Data. Journal of Food Protection, 83(12), 2087-2094. https://doi.org/10.4315/JFP-20-151

\section{General rights}

Copyright and moral rights for the publications made accessible in the public portal are retained by the authors and/or other copyright owners and it is a condition of accessing publications that users recognise and abide by the legal requirements associated with these rights.

- Users may download and print one copy of any publication from the public portal for the purpose of private study or research.

- You may not further distribute the material or use it for any profit-making activity or commercial gain

- You may freely distribute the URL identifying the publication in the public portal 
2 Research Paper

3 Running head: Source attribution of foodborne diseases in Japan

4

5

6

Attributing human foodborne diseases to food sources and water in Japan using analysis of 7 outbreak surveillance data

8

9

Yuko Kumagai $^{{ }^{*} \text {, Sara Monteiro Pires }}{ }^{2}$, Kunihiro Kubota ${ }^{3}$, and Hiroshi Asakura ${ }^{3}$

${ }^{1}$ Laboratory of Foodborne Diseases, Department of Human Ecology, The Wayo Women's University,

2-3-1, Kohnodai, Ichicawa City, Chiba, 272-8533, Japan

${ }^{2}$ National Food Institute, Technical University of Denmark, Kemitorvet, Building 201, Room 116, 2800 Kgs. Lyngby, Denmark

${ }^{3}$ National Institute of Health Sciences, 3-25-26, Tonomachi, Kawasaki-ku, Kawasaki City, Kanagawa,

Key words: Source attribution, Foodborne pathogens, Foodborne outbreaks, Foodborne surveillance 
ABSTRACT

In Japan, strategies for ensuring food safety have been developed without reliable scientific evidence on the relation between foodborne diseases and food sources. This study aimed to provide information on the proportions of foodborne diseases caused by seven major causative pathogens (Campylobacter spp., Salmonella spp., enterohemorrhagic Escherichia coli (EHEC), V. parahaemolyticus, Clostridium perfringens, Staphylococcus aureus, and Norovirus) attributed to foods, and to explore factors affecting changes in these source attribution proportions over time using analysis of outbreak surveillance data. For the calculation of the number of outbreaks attributed to each source, simple-food outbreaks were assigned to the single-food category in question, and complex-food outbreaks were classified under each category proportionally to the estimated probability. During 2007-2018, 8,730 outbreaks of foodborne diseases caused by seven pathogens were reported, of which 6,690 (76.6\%) were of unknown source. We estimated the following source attributions proportions of foodborne diseases: chicken products (80.3\%, UI 80.1-80.4) for Campylobacter spp., beef products $(50.1 \%$, UI 47.0-51.5) and vegetables (42.3\%, UI 40.9-45.5) for EHEC, eggs (34.6\%, UI 27.8-41.4), and vegetables (34.4\%, UI 27.8-40.8) for Salmonella spp., finfish (50.3\%, UI 33.3-66.7) and shellfish (49.7\%, UI 33.3-66.7) for V. parahaemolyticus, grains and beans (57.8\%, UI 49.7-64.9) for S. aureus, vegetables (63.6\%, UI 48.5-74.6), chicken products (12.7\%, UI 4.6-21.5) and beef products (11.1\%, UI 8.5-13.1) for $C$. perfringens, and shellfish (75.5\%, UI 74.7-76.2) for Norovirus. In this study, we provide the best currently available evidence based information to evaluate the link between foodborne diseases and foods. Our results on source attribution for Campylobacter spp. and EHEC suggest that the strict health regulations for raw beef were reflected in the proportions of these diseases attributed to this food. 
$49>$ Source attribution proportions of foodborne diseases in Japan were estimated.

$50>$ Source attribution was useful to guide interventions and evaluate their effect.

$51>$ Strict health regulations for raw beef affected source attribution proportions.

52

53 
The preventive management of foodborne diseases has significant public health implications for developing and developed countries $(3,27)$. In Japan, both the overall numbers of reported outbreaks and cases of foodborne diseases are on a decreasing trend, but this trend is not common to all pathogens. The annual number of outbreaks and cases of foodborne diseases caused by Vibrio parahaemolyticus and Salmonella species have decreased substantially (7). In contrast, the annual number of outbreaks of foodborne diseases caused by Campylobacter species and Norovirus has markedly increased (7). In recent years, the following severe outbreaks have occurred in Japan: (i) a large outbreak due to consumption of raw beef products was caused by enterohemorrhagic Escherichia coli (EHEC) and resulted in 205 cases (including five deaths) in 2011; (ii) a large outbreak due to consumption of sushi topped with raw or undercooked chicken meat at an outdoor event was caused by Campylobacter jejuni/coli and resulted in 875 cases in 2016; and (iii) a large outbreak due to consumption of Kizami-nori (chopped seaweed) at schools was caused by Norovirus resulted in 1,084 cases in $2017(15)$

Starting from circa 2000, most developed countries, including Japan, introduced a risk-based approach for the management of public health hazards in foods called the "food risk analysis framework" (28). According to this framework, the authorities responsible for ensuring food safety oversee the overall strategy, with the appropriate preventive programs being implemented throughout the food supply chain by stakeholders, such as farmers, food manufacturing companies, and restaurants. The purposes of these programs are to identify and prioritize food safety measures, and to evaluate the effectiveness of risk management options by the food safety regulators and policy makers. To ensure the maximum effectiveness of preventive programs, it is important to know the contribution of particular foods to the total burden and costs of foodborne disease. For estimating this contribution, several source attribution methods have been implemented, including analyses of outbreak investigations, meta-analyses of case control studies, microbiological sub-typing combined with surveillance, and expert elicitation (4). In Japan, thus far strategies for ensuring food safety have been developed without reliable scientific evidence for the data on the relationship between foodborne diseases caused by pathogens and foods. 
Hence, this study aimed to estimate the proportions of foodborne diseases caused by the seven pathogens (Campylobacter spp., Salmonella spp., EHEC, V. parahaemolyticus, Clostridium perfringens, Staphylococcus aureus, and Norovirus), which have accounted for approximately $87 \%$ of foodborne disease cases in Japan (7), attributed to food sources using an analysis of outbreak data, and to explore factors affecting changes in source attribution proportions over time. This information can assist in the development of further solid, evidence-based strategies for reducing the risk of foodborne diseases in Japan.

\section{MATERIALS AND METHODS}

Data sources. We used three sources to analyze the current situation of foodborne diseases and to estimate the contribution of Campylobacter spp., Salmonella spp., EHEC, V. parahaemolyticus, $C$. perfringens, S. aureus, and Norovirus to foodborne diseases in Japan. The three data sources were: (i) statistics of cases and outbreaks of foodborne diseases compiled by the Ministry of Health, Labour and Welfare (7); (ii) data of outbreak investigations undertaken by local governments (8); and (iii) infectious disease surveillance data on EHEC and Norovirus (5, 6). Data for (i), and (ii) were collected under the Food Sanitation Law, while data for (iii) were collected under the Infectious Diseases Control Law. Collected data covered the period from 2007 to 2018.

Analysis of foodborne diseases outbreaks caused by the seven pathogens. An outbreak was defined as cluster of two or more illnesses. Data were organized so that each row in the data set corresponded to one outbreak. For each outbreak, the following data were collected: number of cases, number of deaths, attack rate (proportion of people who became ill after being exposed to the implicated food), setting, year, and implicated food source. To evaluate whether there were significant differences in the attack rate of foodborne diseases, t-tests were performed.

Food categorization. To categorize foods, we applied the scheme developed by the United States' Interagency Food Safety Analytics Collaboration. (23), allowing for potential adaptations to accommodate sub-categories that are common in Japan. The level of sub-categorization within each 
main food category varied. For example, while for "land animals," the lowest level of subcategorization was used, all fruits and all vegetables were grouped in the higher-level category of "produce." The type of processing or the degree of cooking (i.e. raw, undercooked and well-done) were not included in the categorization scheme.

Analysis of source attribution proportions of foodborne diseases. To be able to evaluate trends over time, we divided the data into two groups: one corresponding to data from 2007 to 2012 (group1), and one corresponding to the data from 2013 to 2018 (group2). This categorization accounted for the impact of strict health regulations regarding the serving of raw beef that were implemented by the Ministry of Health, Labour and Welfare of Japan in 2011 (9) and 2012 (10) as a result of a large outbreak due to consumption of raw beef products contaminated with EHEC.

\section{Model overview}

The method used in this study was based on a method previously published by Pires et.al. (20), that was modified and applied to our dataset. The principle was to attribute human cases to specific food sources based on the number of outbreaks caused by each of these foods. For this purpose, implicated foods were classified by their ingredients as simple (i.e. belonging to one single food category) or complex (i.e. belonging to multiple food categories). The ingredients that constituted the complex foods were designated using defined criteria established by Painter et al. (16). The proportion of disease attributed to each food source was estimated in a two-step process based on a) the number of simple-food outbreaks caused by that source and b) the number of complex-food outbreaks, the ingredients (food categories) composing complex-foods, and the probability that each of these categories was the cause of the complex-food outbreaks. The source attribution proportions were calculated for the whole population (i.e. the data were not categorized by region or age group).

In the first step, the number of simple-food outbreaks attributed to each single food category was calculated. In the second step, we initially calculated $P_{j}$, which refers to the probability that an outbreak was caused by source $j$, by summarizing the data from simple-food outbreaks per source 
across Japan and for the whole study period. Specifically, $P_{j}$ was defined as the proportion of singlefood outbreaks caused by source $j$. The uncertainty in the probability vector $P$ was quantified using a Dirichlet $(S)$ distribution, with the $S$ vector of components $S_{j}$ corresponding to the number of singlefood outbreaks caused by source $j$. Next, complex-food outbreaks were partitioned proportionally to the food categories of the implicated food proportionally to the probability $P_{j}$ of causing a simple-food outbreak. We used the Monte Carlo simulation approach to propagate the uncertainty in $P_{j}$ and to model the uncertain allocation of a complex-food outbreak to a specific food category. First, we simulated 10,000 values of $P_{j}$ for each source $j$. We then multiplied $P_{j}$ by a dummy matrix $F_{i j}$, representing the implicated food categories $j$ in outbreak $i$. For instance, outbreaks caused by lasagna would be attributed to the categories "beef", "vegetables", "grains and beans", and "“dairy"; $F_{i j}$ would thus contain the value 1 for the sources "beef", "vegetables", "grains and beans", and "oils and sugar", and the value 0 for all other sources. By multiplying $F_{i j}$ by $P_{j}$, outbreaks due to a complex food were attributed only to categories that had been implicated in at least one simple-food outbreak. In our example above, if "grains and beans" and "dairy" were not implicated in any pathogen-specific outbreak caused by simple foods, these two categories would be excluded from the attribution assessment of the lasagna outbreak. In the second step of the Monte Carlo process, we accounted for the uncertain allocation of complex-food outbreaks to specific food categories. For each complex-food outbreak $i$ and per iteration of $P_{j}$, we simulated 20 realizations of a multinomial distribution with size 1 and probability vector $P F_{i}$. For each complex-food outbreak $i$, this then resulted in 200,000 random attributions to a single source $j$. Finally, the results of the simple-food outbreaks were summed with the probabilistic attributions of the complex-food outbreaks, to obtain the total number of outbreaks attributed to each source:

$T_{j}=S_{j}+C_{j}$

Where $T_{j}$ is the total number of outbreaks attributed to source $j, S_{j}$ is the number of simple-food outbreaks caused by source $j$, and $C_{j}$ is the number of complex-food outbreaks attributed to source $j$. 
The percentage of disease attributed to each source $j$ and to "unknown source" was then obtained by dividing the total number of attributed outbreaks to the total number of reported outbreaks $T$ :

$100 * T_{j} / T$.

The resulting uncertainty distribution was summarized by its mean and a 95\% uncertainty interval (UI) was given by the distribution's 2.5th and 97.5th percentiles (see the Appendix).

The number of ill people implicated in the outbreaks was not considered in the analysis to avoid potential overestimation of the importance of sources that caused large outbreaks (21). For these statistical analyses, we used Microsoft Excel (2010; Microsoft Corp., Redmond, WA), SPSS for Windows (Version 21; IBM Corp., Armonk, NY), and R 3.5.1, all models were implemented in R 3.5.1 (22).

\section{RESULTS}

Current situation of foodborne diseases caused by seven major pathogens in Japan. The statistics data for foodborne diseases showed that both the number of outbreaks and the number of cases of foodborne diseases are on a declining trend in Japan (Fig. 1). For example, the average number of cases of Campylobacter spp. has decreased over time, except in 2016 when a large Campylobacter spp. outbreak occurred. The attack rate of Campylobacter spp. was higher in 2018 than in 2007 $(p<0.05)$. Although the annual number of cases of foodborne disease caused by EHEC was lower than those caused by other pathogens, there were seven deaths in 2011, eight in 2012, ten in 2016, and one in 2017. The annual number of cases of infection by Salmonella spp., V. parahaemolyticus, S. aureus, and $C$. perfringens were on a declining trend. However, occasional large outbreaks have occurred. The number of cases of Norovirus infection was in the range of $8,475-18,520$, which represents the largest number of cases by any of the causative agents (Table 1). 
Causative foods identified by outbreaks investigations. The average proportions of "complex foods", "simple foods", and "unknown" for Campylobacter spp. were 4.4\%, 21.3\%, and 74.3\%, respectively. The corresponding proportions were 11.4\%, 16.9\%, and 71.7\% for EHEC, 21.5\%, 7.7\%, and $70.8 \%$ for Salmonella spp., $21.7 \%, 10.8 \%$, and $67.5 \%$ for $V$. parahaemolyticus, $31.7 \%, 9.6 \%$ and $58.7 \%$ for S. aureus, $36.0 \%, 6.2 \%$, and $57.8 \%$ for C. perfringens, and $5.9 \%, 10.5 \%$, and $83.5 \%$ for Norovirus (Fig 2). "Complex-foods" are foods belonging to multiple food categories, "simple-foods" are foods belonging to one single food category, and "unknown" refers to food sources that could not be identified.

Estimates for source attribution proportions using outbreak data. Table 2 shows the proportions of foodborne diseases caused by the seven pathogens attributed to food sources and water according to the analysis of the data for the period 2007 to 2018 . We estimated that chicken products were the most important source of foodborne diseases caused by Campylobacter spp. (80.3\%, UI 80.1-80.4), followed by beef products $(10.5 \%$, UI $10.4-10.8)$. A total of $50.1 \%$ of foodborne diseases caused by EHEC could be attributed to beef products (UI 47.0-51.5) and $42.3 \%$ to vegetables (UI 40.9-45.5). Furthermore, $34.6 \%$ of foodborne diseases caused by Salmonella spp. could be attributed to eggs (UI 27.8-41.4), 34.4\% to vegetables (UI 27.8-40.8), $11.6 \%$ to chicken products (UI 8.9-14.8), and 7.2\% to finfish (UI 4.7-10.7). A total of 50.3\% of foodborne diseases caused by V. parahaemolyticus could be attributed to fish (UI 33.3-66.7) and 49.7\% to shellfish (UI 33.3-66.7). Grains and beans were the most important source of foodborne diseases caused by S. aureus (57.8\%, UI 49.7-64.9), followed by vegetable $(11.1 \%$, UI 5.9-17.8). Vegetables were the most important source of foodborne diseases caused by $C$. perfringens (63.6\%, UI 48.5-74.6), followed by chicken products (12.7\%, UI 4.6-21.5) and beef products (11.1\%, UI 8.5-13.1). Shellfish was the most important source of Norovirus, contributing to $75.5 \%$ of foodborne diseases caused by Norovirus (UI 74.7-76.2), followed by grains and beans (9.9\%, UI 7.8-12.1), and vegetables (9.5\%, UI 7.8-11.1). Altogether, we observed the following source attribution proportions of foodborne diseases caused by the seven pathogens from 2007 to 2018: "land animals" (99.0\%) for Campylobacter spp., "land animals" (57.7\%) and "plants" (42.3\%) for EHEC, "land animals" (53,2\%), "aquatic animals" (12,3\%), and "plants" (34.4\%) for 
Salmonella spp., "aquatic animals" (100\%) for V. parahaemolyticus, "land animals" (20.4\%), "aquatic animals" (10.1\%), and "plants" (68.9\%) for S. aureus, "land animals" (24.6\%) and "plants" $(73.1 \%)$ for $C$. perfringens, and "aquatic animals" (78.1\%) and "plants" (20.8\%) for Norovirus. The proportions of foodborne diseases caused by Campylobacter spp., EHEC, and C. perfringens attributed to "beef products" were higher than $10 \%$. We analyzed the data for the periods 2007 to 2012 (group 1) and 2013 to 2018 (group 2) for Campylobacter spp., EHEC, and C. perfringens, respectively (Fig. 3A, Fig. 3B, and Fig. 3C). We observed a substantial increase in the proportion of foodborne disease caused by Campylobacter spp. attributed to chicken products from group 1 (from 2007 to 2012:74.5\%, UI 73.9-74.7) to group 2 (from 2013 to 2018: 92.8\%, UI 92.6-92.8) (Fig. 3A), in the proportion of foodborne diseases caused by EHEC attributed to raw horse meat (from 0\% to 13.8\%), and minor increases in the relative contribution of vegetables (from $39.0 \%$ to $46.2 \%$ ) and chicken products (from $0 \%$ to $3.4 \%$ ) (Fig. 3B). In contrast, the proportion of foodborne disease caused by Campylobacter spp. (from $19.0 \%$ to $2.9 \%$ ) and EHEC (from $61.0 \%$ to $36.5 \%$ ) attributed to beef products decreased in the same period (from 2013 to 2018). However, we observed an increase in the proportion of foodborne diseases caused by $C$. perfringens attributed to beef (from 10.2\% to $13.1 \%$ ) (Fig. 3C).

\section{DISCUSSION}

Our results indicate that foodborne diseases caused by Campylobacter spp. were most often linked to chicken products; those caused by EHEC was found to be linked to beef products and vegetables; Salmonella spp. were attributed to a wide variety of foods (i.e., eggs and vegetables); $V$.

parahaemolyticus most often linked to finfish and shellfish; S. aureus linked to grains and beans; $C$. prefringens linked to vegetables, chicken products and beef products; and Norovirus most often linked to shellfish. Furthermore, our results reflected the impact of strict health regulations for raw beef on changes in source attribution for Campylobacter spp. and EHEC. The decrease in the proportions of foodborne diseases caused by Campylobacter spp. and EHEC attributed to "beef products" in the same period (from 2013 to 2018) may indicate that "beef products" pose a risk for foodborne diseases caused by Campylobacter spp. and EHEC in 2013 were reduced due to the strict health regulations on 
consumption of raw beef introduced by the Ministry of Health, Labour and Welfare of Japan in 2011 (9) and 2012 (10). However the number of outbreaks and cases caused by Campylobacter spp. and EHEC, increased after 2013, returning to the same proportions of before the introduction of strict regulations without major changes. In addition, the number of cases caused by EHEC showed the same tendency as that shown by infectious disease surveillance data $(3,770$ cases in $2012,4,045$ cases in 2013, and 4,156 in 2014) (5). Generally, it has been reported that changes in the number of outbreaks and cases of foodborne diseases are determined by various factors (such as the public health significance of each disease, impact on the food market, consumers' risk perceptions, and public opinion) (28). The cases were reduced for a brief period of time, but this change was not persistent. The further discussion is about how to persistently reduce the number of outbreaks and cases so that they do not start increasing again.

Evaluating links between foodborne diseases and foods provides important scientific evidence for identifying and prioritizing food safety measures and the appropriate preventive programs throughout the food supply chain by stakeholders, such as farmers, food manufacturing companies, and restaurants. Source attribution methodologies have routinely been applied in several countries. These studies demonstrate how source attribution is useful to guide food safety policy and interventions. They also demonstrate that often there are differences in the relative contribution of different foods and routes of transmission of foodborne pathogens in different countries, highlighting the need to national-specific data and source attribution efforts. For example, where the most important source of Campylobacter infections in all countries is poultry, the contribution of beef and meat from other ruminants varies considerably between countries $(1,13,17,24,26)$.

\section{The overall assumption of the source attribution method we applied is that estimated attribution} proportions based on outbreak data can be used to attribute the overall burden of foodborne disease by the seven pathogens (i.e. the total incidence, including both outbreak-associated and sporadic cases) (20). The limitations and uncertainties of this method have been discussed elsewhere $(19,21)$. Overall, estimates inevitably depend on the likelihood of a food being investigated in an outbreak, as well as 
the reporting capacity of the country. To avoid potential overestimation of the importance of sources that have caused a small number of large outbreaks, the number of cases implicated in the outbreaks was not considered in the analysis.

The main objective of this study was to provide information on the proportions of foodborne diseases caused by the seven pathogens attributed to food sources. The information derived from this study could be useful for the development of strategies aimed at reducing the risk of foodborne diseases in Japan. To the best of our knowledge, these estimates provide the best currently available evidencebased information to evaluate the link between foodborne diseases and specific foods. However, our study has several limitations. There are many outbreaks that cannot be attributed to a particular causative food based on investigations by officials in local governments. For example, the proportion of outbreaks caused by Campylobacter spp. of "unknown" food sources was in the range of $73.4 \%$ to 84.0\%. Further, not all foodborne outbreaks could be investigated and not all foodborne outbreaks are reported $(11,12)$. In the future, we hope to improve our knowledge and to estimate source attribution for some of these pathogens using other methods, using microbial subtyping data on the occurrence of pathogens in sources and human cases $(2,14,18,25)$.

\section{ACKNOWLEDGMENTS}

This study was supported by a grant from the Food Safety Commission, Cabinet Office, Government of Japan (Research Program for Risk Assessment Study on Food Safety, No 1806).

\section{Boysen, L., H. Rosenquist, J. T. Larsson, E. M. Nielsen, G. Sorensen, S. Nordentoft, and T. Hald.} 2014. Source attribution of human campylobacteriosis in Denmark. Epidemiol Infect. 142:15991608. https://doi.org/10.1017/S0950268813002719

2. de Knegt, L. V., S. M. Pires, C. Lofstrom, G. Sorensen, K. Pedersen, M. Torpdahl, E. M. Nielsen, and T. Hald. 2016. Application of Molecular Typing Results in Source Attribution Models: The Case of Multiple Locus Variable Number Tandem Repeat Analysis (MLVA) of Salmonella 
Isolates Obtained from Integrated Surveillance in Denmark. Risk Anal. 36:571-88. https://doi.org/10.1111/risa.12483

305

306

307

3. Havelaar, A. H., S. Brul, A. de Jong, R. de Jonge, M. H. Zwietering, and B. H. Ter Kuile. 2010. Future challenges to microbial food safety. Int J Food Microbiol. 139: S79-94. https://doi.org/10.1016/j.ijfoodmicro.2009.10.015

4. Hoffmann, S., B. Devleesschauwer, W. Aspinall, R. Cooke, T. Corrigan, A. Havelaar, F. Angulo, H. Gibb, M. Kirk, R. Lake, N. Speybroeck, P. Torgerson, and T. Hald. 2017. Attribution of global foodborne disease to specific foods: Findings from a World Health Organization structured expert elicitation. PLoS One. 12: e0183641. https://doi.org/10.1371/journal.pone.0183641

5. Japan, National Institute of Infectious Diseases. Infectious Diseases Weekly Survey (IDWR). Available at: http://www.nih.go.jp/niid/en/. Accessed 15 April 2020.

6. Japan, National Institute of Infectious Diseases. Infectious Agents Surveillance Report (IASR) Available at: http://www.nih.go.jp/niid/en/iasr-e.html. Accessed 15 April 2020.

7. Japan, the Ministry of Health, Labour and Welfare. Foodborne diseases statistics (data for foodborne disease outbreaks). Available at: https://www.e-stat.go.jp/statsearch/files?page=1\&toukei=00450191\&tstat=000001040259. Accessed 15 April 2020.

8. Japan, the Ministry of Health, Labour and Welfare. Foodborne diseases statistics (report for investigation of foodborne disease outbreaks). Available at: https://www.mhlw.go.jp/stf/seisakunitsuite/bunya/kenkou_iryou/shokuhin/syokuchu/04.html\#j4-3. Accessed 15 April 2020.

9. Japan, the Ministry of Health, Labour and Welfare. Information on amendment of the Food Sanitation Law related to "raw beef" in 2011. Available at: https://www.mhlw.go.jp/topics/syokuchu/dl/110916_01.pdf. Accessed 15 April 2020.

10. Japan, the Ministry of Health, Labour and Welfare. Information on amendment of the Food Sanitation Law related to "raw beef" in 2012. Available at: https://www.mhlw.go.jp/seisakunitsuite/bunya/kenkou_iryou/shokuhin/syouhisya/110720/dl/1206 25_01.pdf. Accessed 15 April 2020. 
11. Kubota, K., E. Iwasaki, S. Inagaki, T. Nokubo, Y. Sakurai, M. Komatsu, H. Toyofuku, F. Kasuga, F. J. Angulo, and K. Morikawa. 2008. The human health burden of foodborne infections caused by Campylobacter, Salmonella, and Vibrio parahaemolyticus in Miyagi Prefecture, Japan. Foodborne Pathog. Dis. 5:641-648. https://doi.org/10.1089/fpd.2008.0092

12. Kumagai, Y., S. Gilmour, E. Ota, Y. Momose, T. Onishi, V. L. Bilano, F. Kasuga, T. Sekizaki, and K. Shibuya. 2015. Estimating the burden of foodborne diseases in Japan. Bull World Health Organ. 93:540-549C. http://dx.doi.org/10.2471/BLT.14.148056

13. Mossong, J., L. Mughini-Gras, C. Penny, A. Devaux, C. Olinger, S. Losch, H. M. Cauchie, W. van Pelt, and C. Ragimbeau. 2016. Human Campylobacteriosis in Luxembourg, 2010-2013: A CaseControl Study Combined with Multilocus Sequence Typing for Source Attribution and Risk Factor Analysis. Nature Sci Rep. 6:20939. https://doi.org/10.1038/srep20939

14. Mullner, P., G. Jones, A. Noble, S. E. Spencer, S. Hathaway, and N. P. French. 2009. Source attribution of food-borne zoonoses in New Zealand: a modified Hald model. Risk Anal. 29:970-84. https://doi.org/10.1111/j.1539-6924.2009.01224.x|

15. Noda, M. 2017. Lessons learned from a large and diffuse outbreak of gastroenteritis caused by consumption of Kizami-nori (chopped seaweed) contaminated with norovirus. Bulletin, Nath. Inst. Health Sc. 135:6-12.

16. Painter, J. A., T. Ayers, R. Woodruff, E. Blanton, N. Perez, R. M. Hoekstra, P. M. Griffin, and C. Braden. 2009. Recipes for foodborne outbreaks: a scheme for categorizing and grouping implicated foods. Foodborne Pathog. Dis. 6:1259-64. http://doi.org/10.1089/fpd.2009.0350

17. Pijnacker, R., I. H. M. Friesema, L. Mughini Gras, G. R. Lagerweij, W. van Pelt, E. Franz. 2019. Disease burden of food-related pathogens in the Netherlands, 2018. RIVM. Available at: https://www.rivm.nl/publicaties/disease-burden-of-food-related-pathogens-in-netherlands-2018. Accessed 30 May 2020.

18. Pires, S. M., Christensen J. 2017. Source attribution of Campylobacter infections in Denmark. DTU. Available at: https://backend.orbit.dtu.dk/ws/portalfiles/portal/145802383/Report_Source_Attribution_Campylo bacter_FINAL.pdf. Accessed 30 May 2020. 
19. Pires, S. M., S. Majowicz, A. Gill, and B. Devleesschauwer. 2019. Global and regional source attribution of Shiga toxin-producing Escherichia coli infections using analysis of outbreak surveillance data. Epidemiol Infect. 147:e236. https://doi.org/10.1017/S095026881900116X

20. Pires, S. M., A. R. Vieira, E. Perez, E., D. L. F. Wong, and T. Hald. 2011. Attributing human foodborne illness to food sources and water in Latin America and the Caribbean using data from outbreak investigations. Int. J. Food Microbiol. 152: 129-138. http://doi.org/10.1016/j.ijfoodmicro.2011.04.018. http://doi.org/10.1016/j.ijfoodmicro.2011.04.018

21. Pires, S. M., H. Vigre, P. Makela, and T. Hald. 2010. Using outbreak data for source attribution of human salmonellosis and campylobacteriosis in Europe. Foodborne Pathog. Dis. 7:1351-61. https://doi.org/10.1089/fpd.2010.0564

22. R Core Team. (2018). R: a language and environment for statistical computing. Retrieved October 15. 2018, from https://www.gbif.org/tool/81287/r-a-language-and-environment-for-statisticalcomputing.

23. Richardson, L. C., M. C. Bazaco, C. C. Parker, D. Dewey-Mattia, N. Golden, K. Jones, K. Klontz, C. Travis, J. Z. Kufel, and D. Cole. 2017. An updated scheme for categorizing foods implicated in foodborne disease outbreaks: A tri-agency collaboration. Foodborne Pathog. Dis. 14:701-710. https://doi.org/10.1089/fpd.2017.2324

24. Rosner, B. M., A. Schielke, X. Didelot, F. Kops, J. Breidenbach, N. Willrich, G. Golz, T. Alter, K. Stingl, C. Josenhans, S. Suerbaum, and K. Stark. 2017. A combined case-control and molecular source attribution study of human Campylobacter infections in Germany, 2011-2014. Nature Sci Rep. 7:5139. https://doi.org/10.1038/s41598-017-05227-x

25. Thepault, A., V. Rose, S. Quesne, T. Poezevara, V. Beven, E. Hirchaud, F. Touzain, P. Lucas, G. Meric, L. Mageiros, S. K. Sheppard, M. Chemaly, and K. Rivoal. 2018. Ruminant and chicken: important sources of campylobacteriosis in France despite a variation of source attribution in 2009 and 2015. Nature Sci Rep. 8:9305. https://doi.org/10.1038/s41598-018-27558-z

26. The United States. Interagency Food Safety Analytics Collaboration (FSAC). 2019. Foodborne illness source attribution estimates for 2017 for Salmonella, Escherichia coli O157, Listeria monocytogenes, and Campylobacter using multi-year outbreak surveillance data, United States. 

Accessed 30 May 2020.

27. The World Health Organization. Initiative to estimate the global burden of foodborne diseases. Available at: http://www.who.int/foodsafety/foodborne_disease/Summary_Doc.pdf?ua=1 . Accessed 15 April 2020.

28. The World Health Organization. Food safety risk analysis - a guide for national food safety authorities. Available at: http://www.who.int/foodsafety/publications/micro/riskanalysis06.pdf?ua=1. Accessed 15 April 2020.

395

\section{FIGURE LEGENDS}

397

FIGURE 1. Annual change in the number of foodborne diseases (outbreaks and cases) according to

398 Foodborne Diseases Statistics by the Ministry of Health, Labour and Welfare in Japan (2000-2018).

399 FIGURE 2. Means of the proportions of "Simple foods," "Complex foods," and "Unknown” for seven 400 pathogens according to Foodborne Diseases Statistics by the Ministry of Health, Labour and Welfare 401 in Japan (2000-2018).

402 FIGURE 3. Comparison of the proportions of foodborne diseases caused by Campylobacter spp., EHEC, and C. perfrigens attributed to food sources and water according to the analysis of the data from 2007-2012 (group 1) and 2013-2018 (group 2). Sections A, B, and C represent the comparative data for Campylobacter spp., EHEC, or C. perfringens, respectively. The dot represents the median estimate; the line represent the $95 \%$ uncertainty interval. 
TABLE 1. Annual changes in cases foodborne diseases caused by seven major pathogens from 2007 to 2018 in Japan (part1 of 2)

\begin{tabular}{|c|c|c|c|c|c|c|c|c|c|c|c|c|c|c|c|c|}
\hline \multirow[b]{2}{*}{ Year } & \multicolumn{4}{|c|}{ Campylobacter spp. } & \multicolumn{4}{|c|}{ EHEC } & \multicolumn{4}{|c|}{ Salmonella spp. } & \multicolumn{4}{|c|}{ V. parahaemolyticus } \\
\hline & Outbreaks & Cases & Deaths & $\begin{array}{c}\text { Attack } \\
\text { rate }^{\mathrm{a}} \\
(\%)\end{array}$ & Outbreaks & Cases & Deaths & $\begin{array}{c}\text { Attack } \\
\text { rate }^{\mathrm{a}} \\
(\%)\end{array}$ & Outbreaks & Cases & Deaths & $\begin{array}{c}\text { Attack } \\
\text { rate }^{\mathrm{a}} \\
(\%)\end{array}$ & Outbreaks & Cases & Deaths & $\begin{array}{c}\text { Attack } \\
\text { rate }^{\mathrm{a}} \\
(\%)\end{array}$ \\
\hline 2007 & 216 & 2,305 & 0 & 56.6 & 24 & 927 & 0 & 40.7 & 105 & 3,756 & 0 & 58.3 & 33 & 1,302 & 0 & 44.2 \\
\hline 2008 & 303 & 2,960 & 0 & 60.2 & 17 & 115 & 0 & 31.5 & 87 & 2,539 & 0 & 52.1 & 10 & 161 & 0 & 54.1 \\
\hline 2009 & 211 & 2,072 & 0 & 60.2 & 21 & 176 & 0 & 36.3 & 63 & 1,514 & 0 & 60.3 & 13 & 279 & 0 & 45.3 \\
\hline 2010 & 242 & 1,985 & 0 & 58.6 & 23 & 354 & 0 & 29.4 & 69 & 2,483 & 0 & 53.6 & 33 & 576 & 0 & 53.1 \\
\hline 2011 & 256 & 2,261 & 0 & 58.5 & 24 & 713 & 7 & 38.2 & 59 & 3,075 & 3 & 65.2 & 8 & 86 & 0 & 61.4 \\
\hline 2012 & 195 & 1,796 & 0 & 60.1 & 17 & 398 & 8 & 37.4 & 34 & 664 & 8 & 64.2 & 8 & 123 & 0 & 35.2 \\
\hline 2013 & 173 & 1,572 & 0 & 61.2 & 13 & 105 & 0 & 34.0 & 32 & 859 & 0 & 48.7 & 8 & 163 & 0 & 35.6 \\
\hline 2014 & 244 & 1,831 & 0 & 63.2 & 20 & 761 & 0 & 31.1 & 31 & 436 & 0 & 61.0 & 6 & 47 & 0 & 56.7 \\
\hline 2015 & 277 & 2,048 & 0 & 62.8 & 17 & 156 & 0 & 50.4 & 23 & 1,917 & 0 & 59.6 & 3 & 224 & 0 & 31.6 \\
\hline 2016 & 321 & 3,254 & 0 & 61.2 & 14 & 252 & 10 & 36.2 & 32 & 791 & 0 & 53.6 & 9 & 237 & 0 & 37.2 \\
\hline 2017 & 309 & 2,433 & 0 & 60.4 & 17 & 168 & 1 & 39.3 & 33 & 1,181 & 0 & 51.7 & 5 & 95 & 0 & 64.5 \\
\hline 2018 & 313 & 1,989 & 0 & 61.4 & 30 & 454 & 0 & 39.7 & 17 & 639 & 0 & 57.9 & 21 & 221 & 0 & 52.5 \\
\hline
\end{tabular}

${ }^{a}$ Mean attack rate. 
TABLE 1 Annual changes in cases foodborne diseases caused by seven major pathogens from 2007 to 2018 in Japan (part 2 of 2)

\begin{tabular}{cccccccccccccc}
\hline \multicolumn{1}{c}{ S. aureus } & \multicolumn{1}{c}{ C. perfringens } & \multicolumn{3}{c}{ Norovirus } \\
\hline Year & Outbreaks & Cases & Deaths & $\begin{array}{c}\text { Attack } \\
\text { rate } \\
(\%)\end{array}$ & Outbreaks & Cases & Deaths & $\begin{array}{c}\text { Attack } \\
\text { rate }^{\mathrm{a}} \\
(\%)\end{array}$ & Outbreaks & Cases & $\begin{array}{c}\text { Deaths } \\
\begin{array}{c}\text { Attack } \\
\text { rate } \\
(\%)\end{array}\end{array}$ \\
\hline 2007 & 69 & 1,180 & 0 & 46.7 & 27 & 2,772 & 0 & 40.6 & 344 & 18,520 & 0 & 47.7 \\
2008 & 56 & 1,422 & 0 & 52.4 & 32 & 2,033 & 0 & 45.1 & 264 & 10,319 & 0 & 52.7 \\
2009 & 41 & 690 & 0 & 52.4 & 20 & 1,566 & 0 & 39.8 & 288 & 10,874 & 0 & 52.1 \\
2010 & 33 & 836 & 0 & 45.2 & 24 & 1,151 & 0 & 50.9 & 399 & 13,904 & 0 & 52.4 \\
2011 & 37 & 792 & 0 & 50.9 & 24 & 2,784 & 0 & 55.3 & 296 & 8,682 & 0 & 55.9 \\
2012 & 42 & 852 & 0 & 51.2 & 26 & 1,597 & 0 & 37.2 & 417 & 17,694 & 0 & 53.1 \\
2013 & 29 & 654 & 0 & 42.6 & 19 & 854 & 0 & 57.3 & 328 & 12,672 & 0 & 51.8 \\
2014 & 26 & 1,277 & 0 & 49.5 & 25 & 2,373 & 0 & 55.5 & 293 & 10,506 & 0 & 50.9 \\
2015 & 33 & 619 & 0 & 44.6 & 21 & 551 & 0 & 51.4 & 482 & 14,880 & 0 & 53.5 \\
2016 & 35 & 697 & 0 & 45.6 & 31 & 1,411 & 0 & 45.5 & 354 & 11,397 & 0 & 55.6 \\
2017 & 21 & 335 & 0 & 43.8 & 27 & 1,220 & 0 & 50.6 & 214 & 8,496 & 0 & 52.8 \\
2018 & 26 & 405 & 0 & 52.5 & 32 & 2,319 & 0 & 49.9 & 256 & 8,475 & 0 & 55.0 \\
\hline
\end{tabular}

411

${ }^{a}$ Mean attack rate. 
TABLE 2. Estimates for $P_{-} j$ for food sources and water for the seven pathogens (from 2007 to 2018)

\begin{tabular}{|c|c|c|c|c|c|c|c|}
\hline & Campylobacter spp. & EHEC & Salmonella spp. & V. parahaemolyticus & S. aureus & C. perfringens & Norovirus \\
\hline \multicolumn{8}{|c|}{ Land animals } \\
\hline Beef & $10.5(10.4-10.8)$ & $50.1(47.0-51.5)$ & $2.2(1.2-4.1)$ & $0(0-0)$ & $1.9(1.1-3.2)$ & $11.1(8.5-13.1)$ & $0.5(0.5-0.8)$ \\
\hline Chicken & $80.3(80.1-80.4)$ & $1.5(1.5-1.5)$ & $11.6(8.9-14.8)$ & $0(0-0)$ & $5.4(3.2-7.6)$ & $12.7(4.6-21.5)$ & $0.2(0.2-0.3)$ \\
\hline Pork & $0.5(0.5-0.5)$ & $0(0-0)$ & $1.8(1.2-3.6)$ & $0(0-0)$ & $6.5(4.3-9.2)$ & $0(0-0)$ & $0(0-0)$ \\
\hline Horse & $0(0-0)$ & $6.1(6.1-6.1)$ & $0(0-0)$ & $0(0-0)$ & $0(0-0)$ & $0(0-0)$ & $0(0-0)$ \\
\hline Mutton & $0(0-0)$ & $0(0-0)$ & $0(0-0)$ & $0(0-0)$ & $0(0-0)$ & $0(0-0)$ & $0(0-0)$ \\
\hline Lamb & $0(0-0)$ & $0(0-0)$ & $0.6(0.6-0.6)$ & $0(0-0)$ & $0(0-0)$ & $0(0-0)$ & $0(0-0)$ \\
\hline Turkey & $1.8(1.8-1.8)$ & $0(0-0)$ & $0(0-0)$ & $0(0-0)$ & $0(0-0)$ & $0(0-0)$ & $0(0-0)$ \\
\hline Ducks & $0.4(0.4-0.4)$ & $0(0-0)$ & $1.2(1.2-1.2)$ & $0(0-0)$ & $0(0-0)$ & $0.8(0.8-0.8)$ & $0(0-0)$ \\
\hline Poultry & $0(0-0)$ & $0(0-0)$ & $0(0-0)$ & $0(0-0)$ & $0(0-0)$ & $0(0-0)$ & $0(0-0)$ \\
\hline Game & $0.4(0.4-0.4)$ & $0(0-0)$ & $1.2(1.2-1.2)$ & $0(0-0)$ & $0(0-0)$ & $0(0-0)$ & $0(0-0)$ \\
\hline Meat & $4.6(4.6-4.6)$ & $0(0-0)$ & $0(0-0)$ & $0(0-0)$ & $0(0-0)$ & $0(0-0)$ & $0(0-0)$ \\
\hline Dairy & $0.5(0.5-0.5)$ & $0(0-0)$ & $0(0-0)$ & $0(0-0)$ & $2.6(2.2-3.8)$ & $0(0-0)$ & $0(0-0)$ \\
\hline Goats milk & $0(0-0)$ & $0(0-0)$ & $0(0-0)$ & $0(0-0)$ & $0(0-0)$ & $0(0-0)$ & $0(0-0)$ \\
\hline Eggs & $0(0-0)$ & $0(0-0)$ & $34.6(27.8-41.4)$ & $0(0-0)$ & $4(1.1-8.1)$ & $0(0-0)$ & $0(0-0)$ \\
\hline
\end{tabular}




\begin{tabular}{|c|c|c|c|c|c|c|c|}
\hline \multicolumn{8}{|c|}{ Aquatic animals } \\
\hline Finfish & $0.5(0.5-0.5)$ & $0(0-0)$ & $7.2(4.7-10.7)$ & $50.3(33.3-66.7)$ & $8.8(5.4-12.4)$ & $0(0-0)$ & $1.2(0.8-1.8)$ \\
\hline Shellfish & $0(0-0)$ & $0(0-0)$ & $2.5(1.2-5.3)$ & 49.7(33.3-66.7) & $0(0-0)$ & $2.3(0.8-4.6)$ & $75.5(74.7-76.2)$ \\
\hline Seaweed & $0(0-0)$ & $0(0-0)$ & $0(0-0)$ & $0(0-0)$ & $0(0-0)$ & $0(0-0)$ & $1.4(0.7-2.3)$ \\
\hline Seafood & $0(0-0)$ & $0(0-0)$ & $2.6(2.4-3.6)$ & $0(0-0)$ & $1.3(0.5-3.8)$ & $0(0-0)$ & $0(0-0)$ \\
\hline \multicolumn{8}{|l|}{ Plants } \\
\hline Vegetables & $0(0-0)$ & $42.3(40.9-45.5)$ & $34.4(27.8-40.8)$ & $0(0-0)$ & $11.1(5.9-17.8)$ & $63.6(48.5-74.6)$ & $9.5(7.8-11.1)$ \\
\hline Fruits/Nuts & $0(0-0)$ & $0(0-0)$ & $0(0-0)$ & $0(0-0)$ & $0(0-0)$ & $0(0-0)$ & $1.4(1-2)$ \\
\hline Oils/Sugar & $0(0-0)$ & $0(0-0)$ & $0(0-0)$ & $0(0-0)$ & $0(0-0)$ & $0(0-0)$ & $0(0-0)$ \\
\hline Grains/Beans & $0(0-0)$ & $0(0-0)$ & $0(0-0)$ & $0(0-0)$ & $57.8(49.7-64.9)$ & $9.5(4.6-19.2)$ & $9.9(7.8-12.1)$ \\
\hline \multicolumn{8}{|l|}{ Others } \\
\hline Water & $0.5(0.5-0.5)$ & $0(0-0)$ & $0(0-0)$ & $0(0-0)$ & $0.5(0.5-0.5)$ & $0(0-0)$ & $0.5(0.5-0.5)$ \\
\hline
\end{tabular}

Note: Data are presented as mean \% (95\% uncertainty interval) 
